\title{
Improved Neuroprotection with Hypothermia Delayed by 6 Hours Following Cerebral Hypoxia-Ischemia in the 14-Day-Old Rat
}

\author{
DEANNA L. TAYLOR, HUSEYIN MEHMET, ERNEST B. CADY, AND A. DAVID EDWARDS \\ Weston Laboratory [D.L.T., H.M., A.D.E], Division of Paediatrics, Obstetrics and Gynaecology, Imperial \\ College School of Medicine, Hammersmith Hospital, London, UK, and Department of Medical Physics \\ and Bioengineering [E.B.C.], University College London Hospitals, London, UK.
}

\begin{abstract}
Since hypothermia may be a potential treatment for perinatal cerebral hypoxic-ischemic injury, we used an established neonatal model of hypoxia-ischemia to determine the time after injury at which cooling had the best protective effect. Fourteen-day-old Wistar rats were subjected to right carotid artery ligation and hypoxia $\left(8 \% \mathrm{O}_{2}\right.$ for $\left.90 \mathrm{~min}\right)$. Immediately at the end of hypoxia (defined as $0 \mathrm{~h}$ ), animals were either maintained at normal body temperature until sacrifice (normothermia) or subjected to hypothermia. In a preliminary study, the effects of a reduction in temperature and the duration of such cooling were investigated; animals were cooled (until brain temperature reached $33^{\circ} \mathrm{C}$ or $30^{\circ} \mathrm{C}$ ) for 2,4 , or $6 \mathrm{~h}$ commencing immediately after hypoxia. In a second study, animals were cooled (brain temperature $30^{\circ} \mathrm{C}$ ) for $6 \mathrm{~h}$ commencing at either $0,2,4$, or $6 \mathrm{~h}$ after the end of hypoxia. Sham-operated animals were used as controls. Twentyfour hours after hypoxia-ischemia, cerebral energy metabolism was measured by phosphorus magnetic resonance spectroscopy, and at $5 \mathrm{~d}$ cerebral infarction was measured by planimetry. In
\end{abstract}

\section{ABSTRACT}

normothermic animals the ratio of phosphocreatine/inorganic phosphate $(\mathrm{PCr} / \mathrm{Pi})$ had fallen markedly $24 \mathrm{~h}$ following hypoxiaischemia. In contrast, animals cooled between 6 and $12 \mathrm{~h}$ displayed high $\mathrm{PCr} / \mathrm{Pi}$ ratios similar to those in control animals. Similarly, after $5 \mathrm{~d}$, infarct area was significantly reduced only in animals cooled between 6 and12 h after injury. These results indicate that cooling between 6 and $12 \mathrm{~h}$ after hypoxia-ischemia is more effective in reducing cerebral injury than other cooling regimes and suggest that the physiologic events during this period are critical for understanding cerebral infarction. (Pediatr Res 51: 13-19, 2002)
Abbreviations
${ }^{31} \mathbf{P}$ MRS, phosphorus magnetic resonance spectroscopy
PCr, phosphocreatine
Pi, inorganic phosphate
HI, hypoxia, ischemia
PFA, paraformaldehyde

Term infants who suffer significant hypoxia-ischemia (HI) during birth later develop cerebral injury and neurodevelopmental impairment that may in the severest cases prove fatal. Studies using phosphorus magnetic resonance spectroscopy $\left({ }^{31} \mathrm{P}\right.$ MRS $)$ have demonstrated that these babies usually possess normal cerebral energy metabolism soon after resuscitation, but impaired oxidative phosphorylation, measured as the ratio of the concentrations of phosphocreatine/inorganic phosphate $(\mathrm{PCr} / \mathrm{Pi})$, develops some $24 \mathrm{~h}$ later as demonstrated by a low $\mathrm{PCr} / \mathrm{Pi}$ that persists for many days (1). This delayed impairment of energy metabolism was not due to continued HI, nor was it associated with intracellular acidosis (2), but its magni-

Received September 6, 2000; accepted August 2, 2001

Correspondence and reprint requests: Dr. Huseyin Mehmet, Weston Laboratory, Institute of Reproductive and Developmental Biology, Division of Paediatrics, Obstetrics and Gynaecology, Imperial College School of Science, Technology and Medicine, Hammersmith Hospital, Du Cane Road, London, W12 0NN, U.K; e-mail: h.mehmet@ic.ac.uk

This work was funded by the Wellcome Trust (Grant No. 046343/z/95). tude was linearly related to the severity of later impairment and reduced brain growth (3).

A similar pattern of changes has been observed in neonatal animal models of HI (4-6). Recently, we have shown that changes comparable to those observed in human term infants occur in a neonatal rat model of $\mathrm{HI}(5,7)$. Thus, in the 7-day-old rat, HI produces a severe disruption of cerebral energy metabolism during the insult, which resolves on reoxygenation. However, there is a second decline in energy metabolites beginning some 10 to $12 \mathrm{~h}$ after the insult $(5,7)$. The decrease in $\mathrm{PCr} / \mathrm{Pi}$ at 10 to $12 \mathrm{~h}$ is related to outcome; animals with a more severe impairment of energy metabolism develop more extensive cerebral injury on the basis of histologic examination (5). Therefore, this model provides us with a useful experimental system to investigate the underlying mechanisms that control cerebral energy metabolism.

The importance of cerebral temperature during and immediately after $\mathrm{HI}$ in determining outcome has been highlighted by a number of studies (8-12). Hypothermia during HI has 
been shown to prevent or delay HI brain injury $(9,13-17)$. However, evidence for a potential beneficial effect of postinsult hypothermia in neonatal animal models of $\mathrm{HI}$ has been conflicting, with studies showing varying degrees of protection for different periods and depths of hypothermia (18-20). Moreover, as the mechanisms of cerebroprotection remain unknown, optimal cooling conditions have proved difficult to establish.

Since the definition of a critical period for the application of hypothermia might help determine the mechanism of action, the aim of this study was to investigate whether mild or moderate hypothermia, the length of the cooling period, or the period of time before initiation of cooling is initiated affected the outcome. Using an established neonatal rat model of $\mathrm{HI}$ and delayed energy failure (5), this study investigated the effect of postinsult hypothermia to see if commencing and ending cooling at different times and at different target temperatures within the first $12 \mathrm{~h}$ after a hypoxic-ischemic insult altered the degree of cerebral damage. The two outcome measures were cerebral energy metabolism, measured as $\mathrm{PCr} / \mathrm{Pi}$ ratio at $24 \mathrm{~h}$ after the hypoxic-ischemic insult, and planimetry to determine the extent of tissue infarction at $5 \mathrm{~d}$.

\section{METHODS}

\section{In Vivo Experiments}

Wistar dams and their litters were maintained on a 12-h cycle of light and dark with food and water freely available. Fourteen-day-old pups of either sex weighing 25-34 g were removed from the litters for preparation and study, and returned to be suckled by their dams at all other times. All animal procedures used done in accordance with the Home Office guidelines and specifically licensed under the Animals (Scientific Procedures) Act, 1986 (U.K.). Anesthesia was induced and maintained with halothane ( $5 \%$ and $1 \%$ to $2 \%$, respectively) in oxygen:nitrous oxide (1:1). Animals underwent ventral midline cervical incision and permanent right carotid artery ligation, with the procedure lasting 5-6 min. Animals were allowed to regain consciousness and were then placed in a Perspex box within a standard neonatal incubator (Vickers plc, U.K.) at 34 $\pm 0.5^{\circ} \mathrm{C}$ with a relative humidity of $>80 \%$ in air. After $60 \mathrm{~min}$, hypoxia was induced by rapidly changing the air in the incubator to $8 \%$ oxygen $/ 92 \%$ nitrogen for $90 \mathrm{~min}$ at the same temperature and humidity. Animals were then removed, and either returned to their dam immediately or following a defined period of hypothermia.

\section{Brain Temperature Measurement}

Brain temperature was continuously measured in one animal in each experimental group using a telemetric temperaturemonitoring probe. Under halothane anesthesia, a brain temperature probe (length $3 \mathrm{~mm}$, model XM-FM, Mini-Mitter, Sunriver, OR, U.S.A.) was implanted through a small burr hole in the skull into the right hippocampus $(3.0 \mathrm{~mm}$ anterior and 4.0 $\mathrm{mm}$ laterally to the interaural line), and secured with dental cement. The animal was allowed to recover and was kept with the experimental animals. An FM receiver (Model TR3000, Mini-Mitter) that was placed in the incubator and interfaced to a computer allowed brain temperature to be recorded continuously. At the end of each experiment, the animal was killed and temperature probe placement confirmed by direct visualization of the probe after coronal sectioning.

\section{Hypothermia}

To induce hypothermia, animals were placed in a purposebuilt Perspex box surrounded by a water jacket through which cooled water was constantly passed. The temperature inside the box could be accurately controlled by altering the temperature of the circulating water. Animals were placed in small wire boxes within the cooling box to keep them separate during the period of cooling.

\section{${ }^{31} \mathrm{P}$ Magnetic Resonance Spectroscopy}

MRS was performed using a 7T Bruker Biospec magnetic resonance spectrometer (Bruker, Germany) operating at 121.6 $\mathrm{MHz}$ for ${ }^{31} \mathrm{P}$. A two turn elliptical $(5 \times 10 \mathrm{~mm})$ surface coil with the major axis parallel to the midline was placed on the right side of the shaven vault of the head to completely cover the expected region of cerebral damage. The volume of brain assessed was predominantly the right forebrain hemisphere such that the anterior margin of the coil lay at a point corresponding to approximately $2 \mathrm{~mm}$ anterior to the bregma and the posterior margin at a point corresponding to the lambdoid suture of the skull, to a depth of approximately $5 \mathrm{~mm}$. The corresponding volume of interest was approximately $100 \mathrm{~mm}^{3}$.

The homogeneity of the static magnetic field was optimized for each subject using the proton MRS water signal. Fullyrelaxed ${ }^{31} \mathrm{P}$ spectra were then obtained using a single pulse acquisition, a 10 second repetition time, and a $180^{\circ}$ flip angle at the coil center. A total of 128 summed free induction decays were obtained for each spectrum. The spectra were analyzed using semi-automatic Lorentzian fitting by $\chi^{2}$ minimization in the frequency domain, and the relative concentrations of $\mathrm{PCr}$ and $\mathrm{Pi}$ were calculated. The concentration ratio $\mathrm{PCr} / \mathrm{Pi}$ was used as a measure of cerebral phosphorylation potential. Data were collected from individual animals while they were anesthetized with halothane $(0.8-1.2 \%)$ and gently restrained on a purpose-built platform introduced into the bore of the magnetic resonance spectrometer. In all experimental groups, spectra were obtained $24 \mathrm{~h}$ after HI. MRS measurements were obtained as quickly as possible to minimize the changes that could possibly affect results and temperature was controlled during measurements so that any changes were kept to a minimum

\section{Histologic Assessment}

Five days following HI, animals were killed with pentobarbitone (i.p. $30 \mathrm{mg} \cdot \mathrm{kg}^{-1}$ ) and transcardially perfused with 25-30 mL $0.9 \% \mathrm{NaCl}$ followed by $25-30 \mathrm{~mL}$ paraformaldehyde (PFA, $4 \% \mathrm{wt} / \mathrm{vol}$ in $0.9 \% \mathrm{NaCl}$ ). Brains were then removed and fixed overnight in $4 \% \mathrm{PFA}$ at $4{ }^{\circ} \mathrm{C}$ and then transferred to $15 \%$ (wt/vol) sucrose in $\mathrm{PBS}\left(4^{\circ} \mathrm{C}\right)$. Specimens were routinely dehydrated in serial alcohols and paraffin was embedded before sectioning. Sections $(10 \mu \mathrm{m})$ were cut at a 
point corresponding to between 2.6 and $3.2 \mathrm{~mm}$ anterior to the interaural line to show the dorsal hippocampus and neocortex [21 day old; (21)].

Hematoxylin and eosin staining was performed on sections using standard techniques for Cole's hematoxylin. Planimetry was used to quantify the extent of the infarct. Images encompassing the entire section were captured using $1 \times$ magnification, then processed using an image analysis system (Image Proplus, Datacell, Reading, UK). Infarcts were measured as surface areas by planimetry in the same brain region for each animal according to a neuroanatomy atlas as described by us in earlier (5). For each animal, the area of infarction was delineated manually (by an observer blinded to the experimental conditions) and a quantitative index of damage was derived by the following formula to take into account tissue shrinkage due to selective neuronal loss:

$$
\% \text { area of infarct }=\frac{(\text { area left side }- \text { viable area right side })}{(\text { area left side })} \times 100
$$

Infarct data were expressed as a mean area of brain obtained from at least three sections per animal.

\section{Experimental Design}

Effect of ambient temperature on cerebral temperature. Preliminary studies were performed to determine the relationship between ambient and brain temperatures. Animals implanted with a temperature probe were placed at different ambient temperatures and brain temperature was measured continuously. The information obtained from these studies was then used to ascertain the ambient temperatures required to achieve mild and moderate hypothermia (brain temperatures of $33^{\circ} \mathrm{C}$ and $30^{\circ} \mathrm{C}$, respectively).
Effect of the depth and duration of hypothermia initiated immediately after HI. First, we examined the effect on infarct size of different periods of either mild or moderate hypothermia initiated immediately after HI. Three groups of animals were studied: 1) hypoxic-ischemic animals maintained normothermic $(n=12) ; 2)$ hypoxic-ischemic animals with immediate mild hypothermia (brain temperature $\left.33^{\circ} \mathrm{C}\right)(n=21)$; and 3) hypoxic-ischemic animals with immediate moderate hypothermia (brain temperature $\left.30^{\circ} \mathrm{C}\right)(n=23)$ (Fig. $\left.1 A\right)$.

Animals were subjected to $\mathrm{HI}$ as described above. Immediately after hypoxia (time $0 \mathrm{~h}$ ), animals in the normothermic group were removed from the hypoxic chamber and placed with their dam until euthanization (Fig. 1A: N). For immediate mild hypothermia, animals were removed from the hypoxic chamber and placed in the cooling box to achieve a brain temperature of $33^{\circ} \mathrm{C}$ for between either 0 and $2(n=7), 0$ and $4(n=6)$, or 0 and $6(n=8)$ hours after hypoxia, after which they were returned to their dam. In the studies of moderate hypothermia, animals were placed at a lower ambient temperature to achieve brain temperature of $30^{\circ} \mathrm{C}$ for between either 0 and $2(n=6), 0$ and $4(n=8)$, or 0 and $6(n=9)$ hours posthypoxia. Five days after the initial insult, animals were killed and brain tissue was subsequently prepared for planimetry as described earlier.

Effect of moderate hypothermia initiated at defined times following HI. After determining a period of cooling that reduced cerebral injury effectively, a second series of experiments was undertaken to see if hypothermia initiated at different times during the first $12 \mathrm{~h}$ after HI was protective against tissue injury. As in the previous studies, delayed impairment of cerebral energy metabolism was measured by ${ }^{31} \mathrm{P}$ MRS $24 \mathrm{~h}$ after HI, and the brains were examined histologically at $5 \mathrm{~d}$.

A

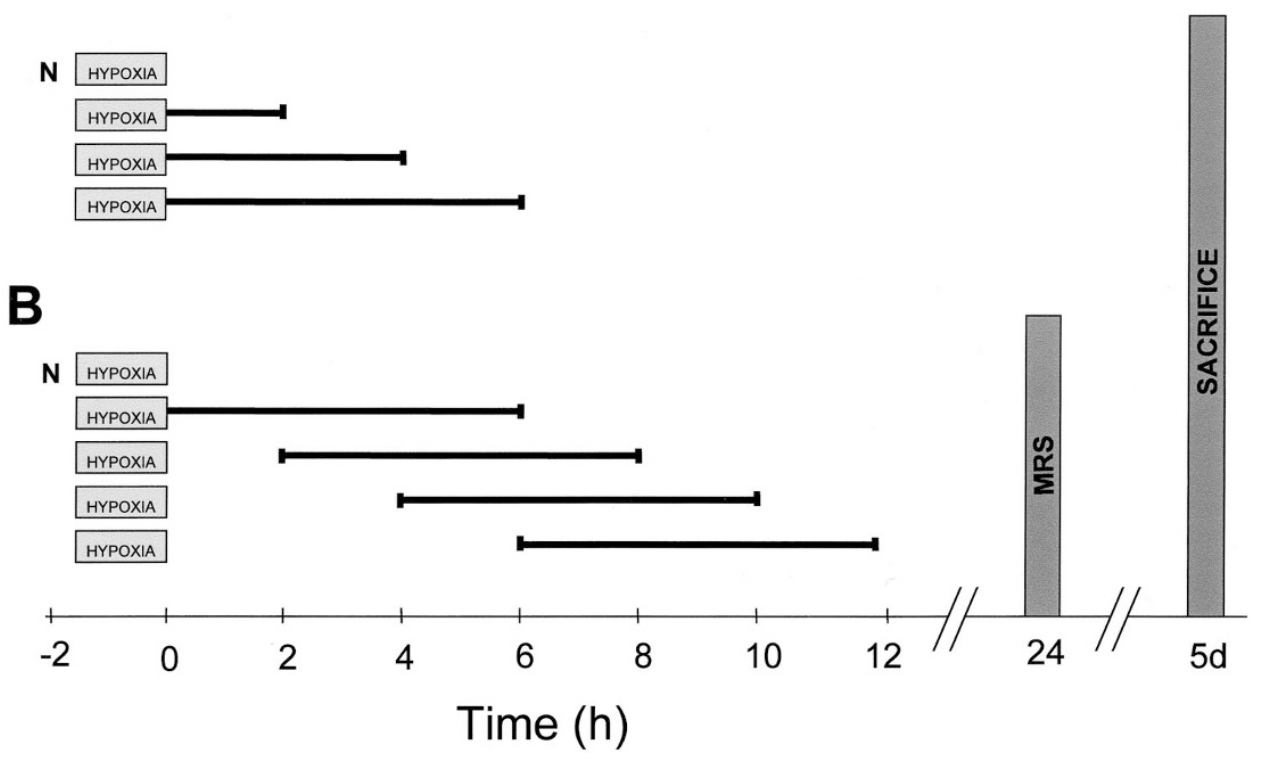

Figure 1. Experimental protocol for hypothermia experiments. Hypothermia was initiated either immediately after hypoxia $(A)$ or at different times within $12 \mathrm{~h}$ of hypoxia $(B)$. The end of the 90 minute hypoxic period is classed as time $0 \mathrm{~h}$. Normothermic animals $(N)$ were not cooled and were returned to their dam until killed at $5 \mathrm{~d}$. Hypothermic animals were placed in the cooling box for the periods indicated by the horizontal bars. MRS was performed at $24 \mathrm{~h}$ after hypoxia and planimetry at $5 \mathrm{~d}$. 
Four groups of animals were studied: 1) hypoxic-ischemic animals which were cooled for a period of $6 \mathrm{~h}$ starting at different times after HI $(n=39)$ (Fig. 1B). 2) hypoxic-ischemic animals which were cooled for $6 \mathrm{~h}$ immediately after HI (i.e. $0-6 \mathrm{~h} ; n=10) ; 3$ ) normothermic hypoxic-ischemic animals ( $n$ =11); and 4) sham-operated animals (i.e. with anesthesia and surgery, but without carotid artery ligation or hypoxia; $n=11)$.

Animals cooled between either 2-8 $(n=10), 4-10(n=$ $14)$, or 6-12 $(n=15)$ hours after hypoxia were replaced with their dam at the end of the hypoxic insult $(0 \mathrm{~h})$ and then transferred into the cooling box at the defined time after hypoxia.

\section{Statistical Analysis}

Infarct data were checked for normality, transformed appropriately, and analyzed by ANOVA using the Bonferroni multiple comparison test. MRS data were found to fit a skewed distribution, and the results were transformed before analysis using a zero-skewness log transformation of the form $y=$ $\ln (x-k)$ where $y$ is the transformed variable, $x$ the original value, and $k$ a coefficient estimated by Newton's method with numeric uncentered derivatives, which allows the skewness of the transformed distribution to be close to zero: $k=3.6196$. Calculations were made using STATA statistical software (Statacorp, College Station, TX, U.S.A.).

\section{RESULTS}

\section{Effect of Ambient Temperature on Brain Temperature}

Direct measurement of brain temperature in the 14-d-old rat showed that ambient temperature exerted marked effects on brain temperature (Fig. 2). When an animal was kept at an ambient temperature of $34^{\circ} \mathrm{C}$ (i.e. the temperature in the incubator during hypoxia), the resulting brain temperature was between $36-37^{\circ} \mathrm{C}$. Transferring the animal immediately to the cooling box at an ambient temperature of $21^{\circ} \mathrm{C}$ caused brain temperature to decrease rapidly, reaching about $33^{\circ} \mathrm{C}$ after 25-30 min. When the ambient temperature was returned to $34^{\circ} \mathrm{C}$, brain temperature increased, recovering to a level similar to that observed before the cooling period. A lower ambient temperature (e.g. $18^{\circ} \mathrm{C}$ in Fig. 2) reduced brain temperature even further. By adjusting the ambient temperature within the cooling box, brain temperature could be lowered as desired and kept constant throughout the duration of the cooling period. Ambient temperatures within the box of approximately $21-$ $22^{\circ} \mathrm{C}$ and $17-18^{\circ} \mathrm{C}$ reduced brain temperature to $33^{\circ} \mathrm{C}$ (mild hypothermia) and $31^{\circ} \mathrm{C}$ (moderate hypothermia), respectively.

\section{Effect of Mild and Moderate Hypothermia Initiated Immediately After HI}

Cerebral HI resulted in infarction of forebrain tissue in the region of the middle cerebral artery on the side of carotid artery ligation only. In normothermic animals that were returned to their dam immediately after the insult (brain temperature of approximately $35^{\circ} \mathrm{C}$ ), over $85 \%$ of the tissue on the ipsilateral hemisphere was infarcted $5 \mathrm{~d}$ after HI $(86.9 \pm 2.5 \%$; mean \pm SEM; $n=12$; Fig. 3 ). The longer periods of both mild and

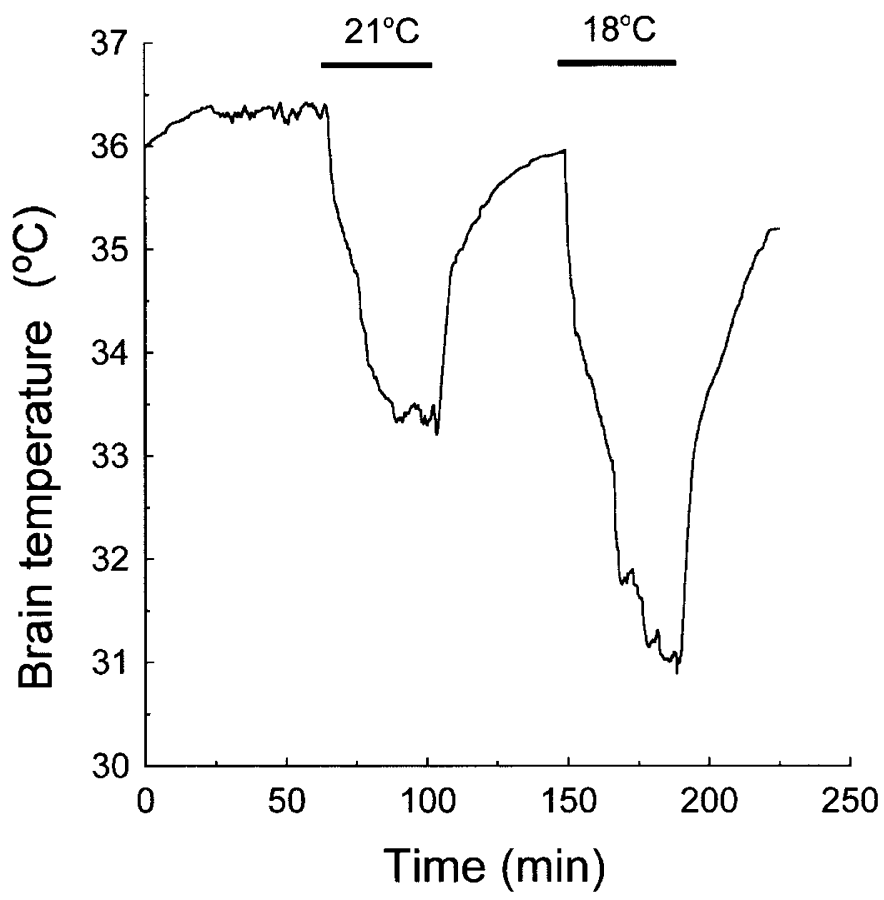

Figure 2. Brain temperature in a 14-d-old rat subjected to changes in ambient temperature. Brain temperature was measured directly with a probe implanted into the right cerebral hemisphere. The animal was kept at $34^{\circ} \mathrm{C}$ before being transferred to the cooling box (at 21 or $18^{\circ} \mathrm{C}$; horizontal bars indicate duration of cooling) to induce hypothermia.

moderate hypothermia initiated immediately after HI significantly reduced infarct area when compared with normothermia. The area of tissue infarction in animals with moderate hypothermia for $0-6 \mathrm{~h}$ after $\mathrm{HI}$ was reduced to $63.9 \pm 3.6 \%$ ( $p$ $<0.05$ ). There was no significant difference in infarct size between mild and moderate hypothermia at any of the cooling times (Fig. 3).

\section{Effect of Moderate Hypothermia Initiated at Different Times After HI}

Control (sham-operated) animals had a mean ( \pm SEM) $\mathrm{PCr} / \mathrm{Pi}$ of $1.64 \pm 0.03(n=11)$ (Fig. 4). At $24 \mathrm{~h}$ after HI, $\mathrm{PCr} / \mathrm{Pi}$ was lower in normothermic hypoxic-ischemic animals $(1.13 \pm 0.01 ; p<0.001)$, indicating a phase of delayed energy impairment. The mean $\mathrm{PCr} / \mathrm{Pi}$ values for animals cooled between 0 and 6,2 and 8,4 and 10 , and 6 and $12 \mathrm{~h}$ after $\mathrm{HI}$ were $1.45 \pm 0.07,1.27 \pm 0.09,1.38 \pm 0.12$, and $1.65 \pm 0.08$, respectively. Only cooling between 6 and $12 \mathrm{~h}$ after HI resulted in $\mathrm{PCr} / \mathrm{Pi}$ higher than in normothermic hypoxic-ischemic animals $(p<0.005)$ and similar to $\mathrm{PCr} / \mathrm{Pi}$ in sham-operated controls.

Five days after HI, the infarct area was measured in the same animals (Fig. 5). In this series, HI in normothermic animals resulted in $65.2 \pm 2.2 \%$ infarction of the tissue on the ipsilateral side. Only cooling between 6 and $12 \mathrm{~h}$ after HI significantly reduced infarct area compared with normothermia to $30.2 \pm 3.3 \%(p<0.001)$.

Normothermic hypoxic-ischemic animals that had a lower $\mathrm{PCr} / \mathrm{Pi}$ ratio at $24 \mathrm{~h}$ developed larger infarct areas at $5 \mathrm{~d}$ (Fig. 6). $\mathrm{PCr} / \mathrm{Pi}$ and infarct area were also correlated in hypothermic 


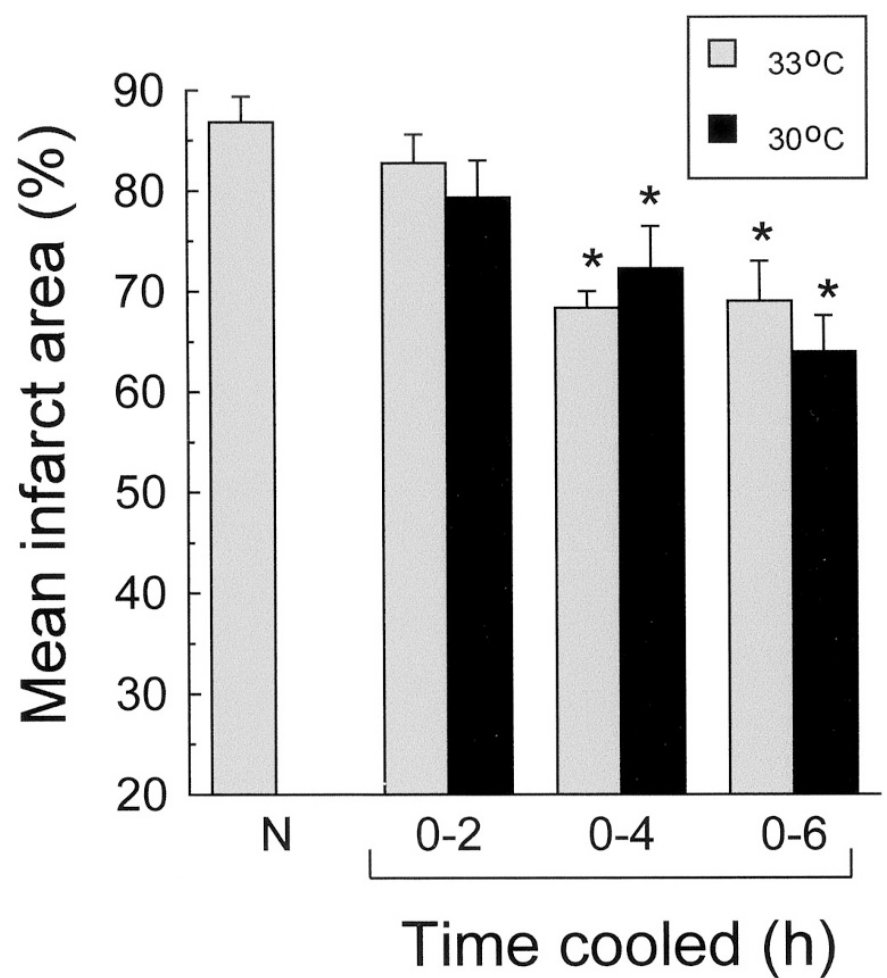

Figure 3. Effect of defined periods of hypothermia initiated immediately after $\mathrm{HI}$ on infarct size at $5 \mathrm{~d}$. Mean infarct area expressed as a percentage of the right side of the brain $( \pm \mathrm{SEM})$ in normothermic animals $(N)$, or those cooled at $0-2,0-4$, or $0-6 \mathrm{~h}$ after $\mathrm{HI}$ with a brain temperature of $33^{\circ} \mathrm{C}$ (gray columns) or $30^{\circ} \mathrm{C}$ (black columns). The longer cooling times significantly decreased infarct area when compared with normothermic animals. ${ }^{*} p<0.05$.

animals, those with higher $\mathrm{PCr} / \mathrm{Pi}$ tended to have smaller areas of tissue infarction. When data from all experimental groups (i.e. not including the sham controls) was pooled (Fig. 6), there was a significant correlation between $\mathrm{PCr} / \mathrm{Pi}$ and infarct size $(\mathrm{r}$ $=0.658 ; p<0.001)$.

\section{DISCUSSION}

The present study has shown that hypothermia after hypoxic-ischemic injury to the developing brain reduces cerebral damage. Outcome was assessed by measuring cerebral energy metabolism at $24 \mathrm{~h}$ and tissue infarction at $5 \mathrm{~d}$. Our findings suggest that cooling between 6 and $12 \mathrm{~h}$ after $\mathrm{HI}$ is more effective at reducing both tissue infarction and the severity of delayed energy impairment than cooling immediately after the insult. In agreement with our previous observations (5), the severity of delayed energy impairment was related to infarct size.

Focal infarction following $\mathrm{HI}$ in the developing brain is a well-characterized and widely used experimental marker of perinatal hypoxic-ischemic injury. This study used 14-d-old rats because at this age, brain development is considered to be comparable to that of a human infant at term (22). Using this model, hypothermic treatment requires that pups are separated from their dam for several hours, implying that hypoglycemia might modulate cerebral damage. However, similar studies have shown that this may not be a major

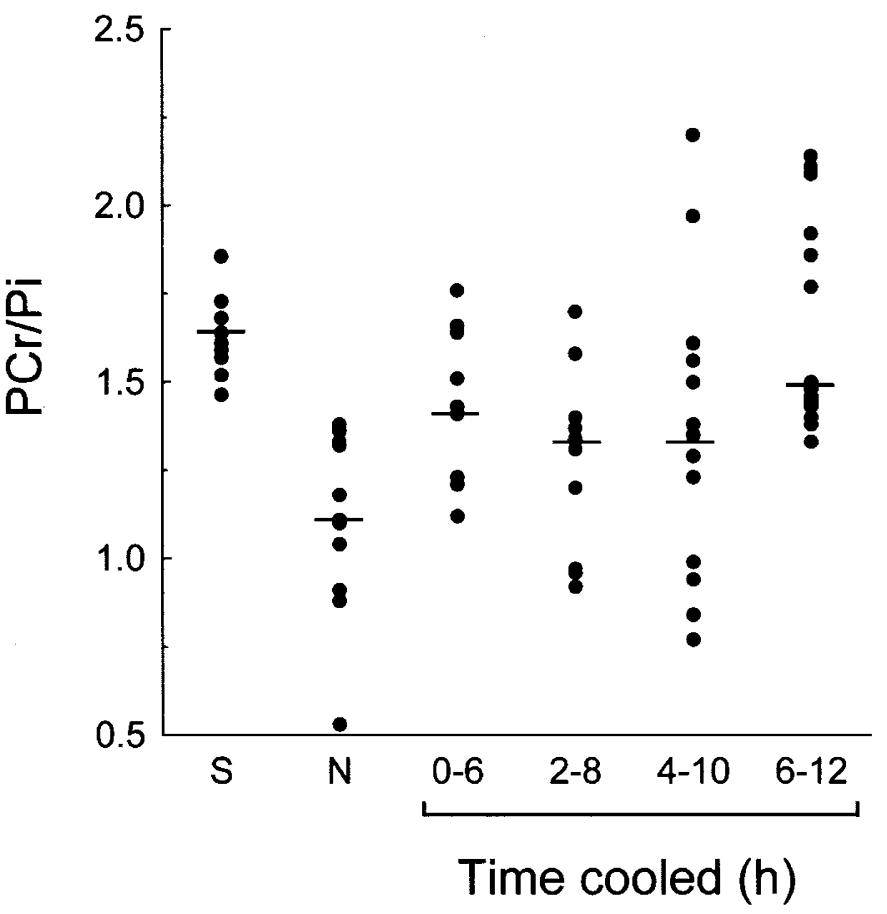

Figure 4. $\mathrm{PCr} / \mathrm{Pi}$ values for individual animals in each experimental group. ${ }^{31} \mathrm{P}$ MRS was used to determine $\mathrm{PCr} / \mathrm{Pi}$ ratios in each rat at $24 \mathrm{~h}$ after cerebral hypoxia ischemia. Sham $(S)$, normothermic HI $(N)$, and cooling (brain temperature $30^{\circ} \mathrm{C}$ ) between 0 and 6,2 and 8,4 and 10 , and 6 and $12 \mathrm{~h}$ after the end of HI. The horizontal line in each data set represents the median $\mathrm{PCr} / \mathrm{Pi}$ value for that group.

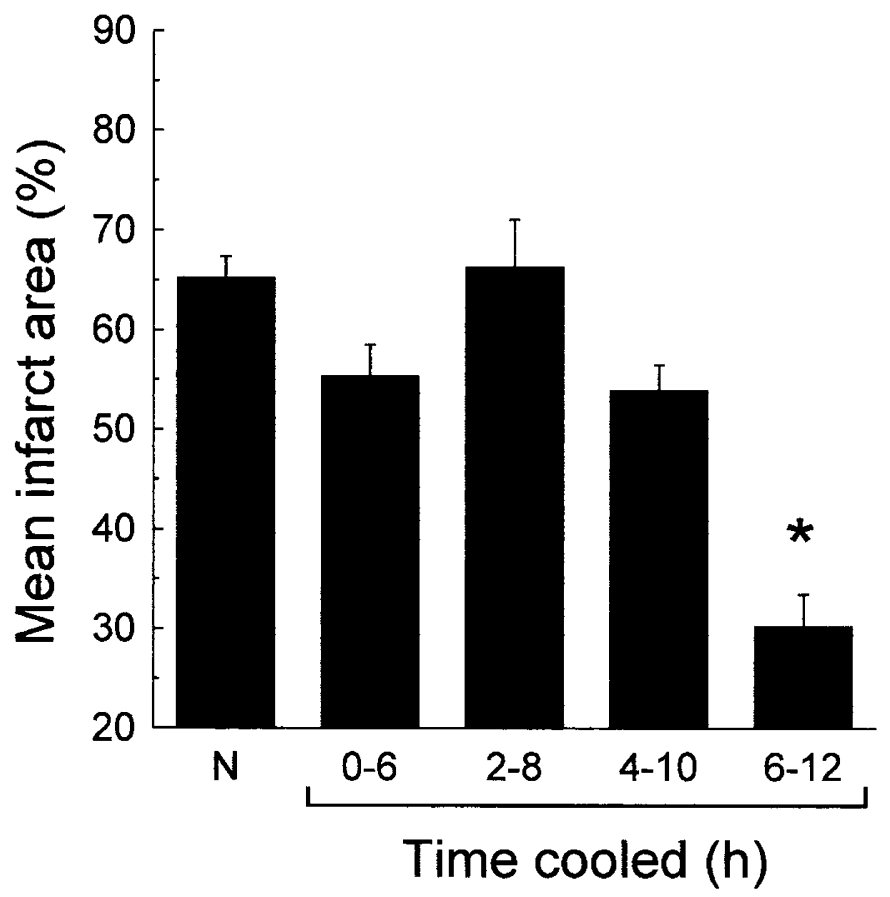

Figure 5. Effect of different cooling times on infarct size at $5 \mathrm{~d}$. Mean infarct area measured by planimetry and expressed as a percentage of the right side of the brain $( \pm$ SEM $)$ in normothermic $(N)$ and hypothermic animals $(* p<0.05$ compared with normothermic animals).

problem because blood glucose and lactate levels in experimental hypothermic animals do not differ from those in controls $(20,23)$. 


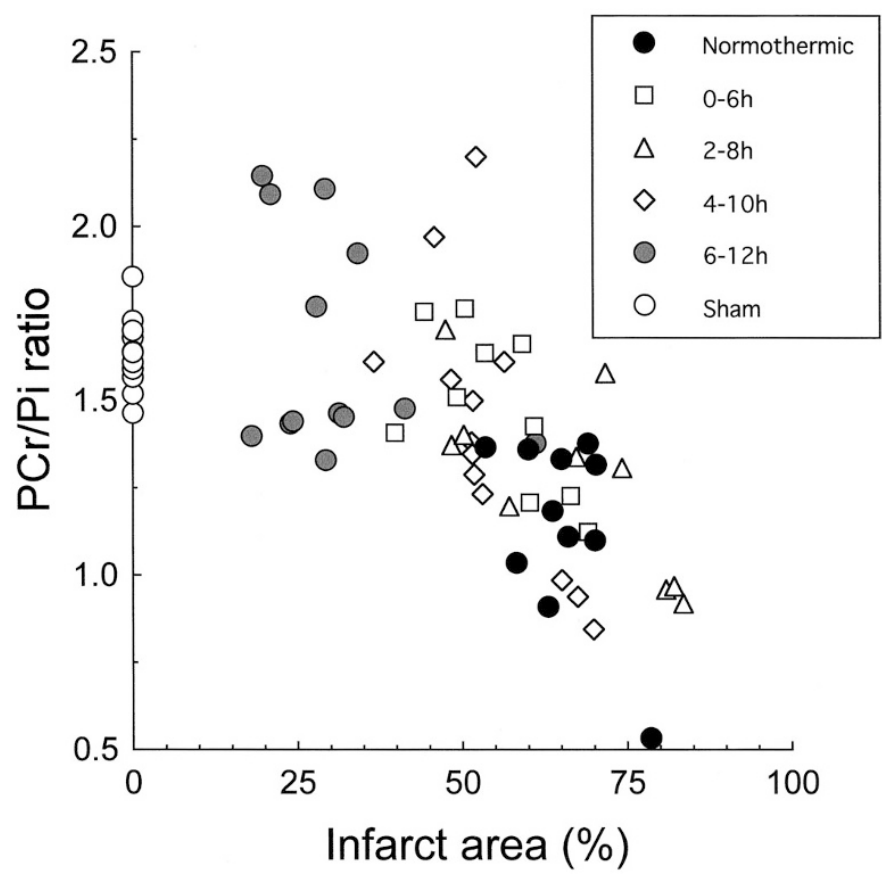

Figure 6. Relationship between cerebral energy metabolism and cerebral damage. Energy metabolism expressed as $\mathrm{PCr} / \mathrm{Pi}$ ratios measured at $24 \mathrm{~h}$ after hypoxia-ischemia against infarct area measured at $5 \mathrm{~d}$ for all the animals in each experimental group.

Cerebral temperature was continuously measured using a telemetric probe, which allowed accurate instantaneous recording within the region of the brain that is primarily affected by the hypoxic-ischemic insult. Implantation of the probe in the same region and to the same depth each time reduced the possible influence of the temperature gradients known to exist within the brain (24). Brain temperature measurements in one animal throughout each experiment were taken as representative of the whole litter and allowed accurate control of the degree of hypothermia. ${ }^{31} \mathrm{P}$ MRS was used to measure cerebral energy metabolism $24 \mathrm{~h}$ after the hypoxic-ischemic insult. $\mathrm{PCr} / \mathrm{Pi}$ values determined in this study were similar to those found previously $(5,6)$, suggesting that the small MRS surface coil localized the data to the area of injury with reasonable precision.

Delayed impairment of cerebral energy metabolism after HI is associated with disrupted oxidative phosphorylation and increased intracellular redox potential (7) that manifest as low $\mathrm{PCr} / \mathrm{Pi}$, increased cerebral lactate concentration, and normal or slightly increased intracellular $\mathrm{pH}$ (2). Previous studies in the 14-d-old rat have shown that delayed impairment of energy metabolism starts by $10 \mathrm{~h}$ after the initial hypoxic-ischemic insult and persists for at least $48 \mathrm{~h}$ (5). In the present study, $\mathrm{PCr} / \mathrm{Pi}$ values $24 \mathrm{~h}$ after $\mathrm{HI}$ in normothermic hypoxic-ischemic animals were similar to those previously reported (5), suggesting that at this time these animals were in the phase of delayed energy impairment. This disruption of oxidative phosphorylation after HI was reduced by postinsult hypothermia, but only if cooling was commenced at $6 \mathrm{~h}$ and ended $12 \mathrm{~h}$ after HI. The groups of animals cooled at other times did not show such an effect. The $\mathrm{PCr} / \mathrm{Pi}$ values for animals cooled between 4 and $10 \mathrm{~h}$ were more widely scattered, with some having values similar to animals cooled between 6 and $12 \mathrm{~h}$ (i.e. with
$\mathrm{PCr} / \mathrm{Pi}$ ratios similar to sham/control animals) and others having much lower values. These findings may suggest that the period when cooling is most effective at improving energy metabolism is after $6 \mathrm{~h}$ following the insult, so animals cooled between 4 and $10 \mathrm{~h}$ may only have a few hours when cooling is most effective, which in most cases may be insufficient to provide protection against secondary impairment and resulting damage.

Five days following HI, normothermic animals developed a large area of tissue infarction on the side of the injury only. Postinsult hypothermia reduced infarct area, with longer periods of cooling providing progressively increased protection. Although this is in agreement with the results obtained in adult animals (25-27), studies using shorter periods of cooling in younger animals have shown contradictory results. Yager et al. (18) observed no protection with postinsult hypothermia in the 7-d old rat; however, using the same model, Thoresen et al. (28) found marked protection with $3 \mathrm{~h}$ of postinsult hypothermia. In the first study experiments were performed while the animals were restrained, whereas in the latter study, as in our experiments, rats were unrestrained. One possibility is that the stress induced by restraining animals can modulate the protective effect of hypothermia (28). In 21-d-old rats, Sirimanne et al. reported that $6 \mathrm{~h}$ of mild hypothermia immediately after hypoxia-ischemia provided no protection against cerebral damage (19), while longer periods of hypothermia (72 h) were protective. In the Sirimanne protocol, brain temperature during the 6-h period of hypothermia did not fall below $35^{\circ} \mathrm{C}$, whereas in the present study, brain temperature in the hypothermic group was maintained at either $30^{\circ} \mathrm{C}$ or $33^{\circ} \mathrm{C}$. It may be that in the earlier study, brain temperatures were not low enough to provide protection against the severe insult. Alternatively, these differences may reflect the distinct developmental stages of the two models.

These differences emphasize the importance of not only the length of cooling and the time of onset after HI, but also of brain temperature. The importance of these three factors is supported in our study by the observation that infarct size in normothermic animals in the first series of experiments (immediate hypothermia) was greater than that in the second series (delayed hypothermia). The major difference between the sets of experiments was that in the second series the ambient temperature of the laboratory was $2{ }^{\circ} \mathrm{C}$ lower when normothermic pups were replaced with their dam. Because there is a close relationship between ambient and cerebral temperatures, it is tempting to speculate that a cooler laboratory temperature may have reduced brain temperature and hence cerebral injury. However, we cannot exclude the possibility that other factors (e.g. minor variations in animal husbandry, genetic background, and differences in time of separation from the dam) may also be involved.

In this study, cooling between 6 and $12 \mathrm{~h}$ after HI provided better protection against infarction than immediate cooling. This protection correlated with the degree of delayed energy impairment; hypothermic animals with higher $\mathrm{PCr} / \mathrm{Pi}$ values at $24 \mathrm{~h}$ had less injury at $5 \mathrm{~d}$. Colbourne and coworkers have found similar protective effects of delayed hypothermia using a four-vessel occlusion model of cerebral ischemia in adults rats (29). Since delaying the onset of cooling appears to provide better protection against hypoxic-ischemic injury, hypothermia may reduce deleterious events that occur during recovery. For 
example, excitotoxicity during reperfusion may be reduced by postinsult hypothermia. Thus, the 7-fold increase in glutamate seen in normothermic animals at this time (11) is not observed in hypothermic animals (30). Similarly, reactive oxygen species that are produced during reperfusion after ischemia have been shown to be involved in cell death (31), and accumulation of lipid peroxidation products and production of free radicals can be suppressed by hypothermia (32-35).

We have previously shown that apoptotic cell death occurs in brain regions sensitive to HI (36) and can be prevented or reduced with hypothermia (37). Based on our earlier studies, postinsult hypothermia selectively blocks apoptosis and not necrotic cell death in neonatal HI (37), although this is not the case in the adult (38). With this fact in mind, results from the present study suggest that the point at which cells are committed to apoptosis has not been reached by $6 \mathrm{~h}$ after HI. This observation widens the therapeutic window available for the treatment of perinatal $\mathrm{HI}$ and also provides the framework to investigate the nature of the critical mechanism.

In summary, this study has shown that the time of cooling and the degree of hypothermia are major variables in the resulting cerebral damage after HI. Specifically, events occurring 6 to $12 \mathrm{~h}$ after $\mathrm{HI}$ are more susceptible to modulation by hypothermia. These results have implications for the practical application of hypothermic neural rescue therapies in birth asphyxia, and imply that adequate time is available for diagnosis before treatment is started, without compromising the efficacy of this therapy.

Acknowledgments. The authors thank Marzena Wylezinska, Department Medical Physics and Bioengineering, University College London Hospitals, for invaluable help with the MRS, and Steve Gentleman, Department of Anatomy, Charing Cross Hospital, for use of the image analysis system.

\section{REFERENCES}

1. Hope PL, Costello AM, Cady EB, Delpy DT, Tofts PS, Chu A, Hamilton PA, Reynolds EOR, Wilkie DR 1984 Cerebral energy metabolism studied with phosphorus NMR spectroscopy in normal and birth-asphyxiated infants. Lancet 2:366-370

2. Azzopardi D, Wyatt JS, Cady EB, Delpy DT, Baudin J Stewart AL Hope PL, Hamilton PA, Reynolds EOR 1989 Prognosis of newborn infants with hypoxicischemic brain injury assessed by phosphorus magnetic resonance spectroscopy. Pediatr Res 25:445-451

3. Roth SC, Baudin J, Cady EB, Johal K, Townsend JP, Wyatt JS, Reynolds EOR, Stewart AL 1997 Relation of deranged neonatal cerebral metabolism with neurodevelopmental outcome and head circumference at 4 years. Dev Med Child Neurol 39:718-725

4. Lorek A, Takei Y, Cady EB, Wyatt JS, Penrice J, Edwards AD, Peebles D, Wylezinska M, Owen-Reece H, Kirkbride V, Cooper C, Aldridge RF, Roth SC, Brown G, Delpy DT, Reynolds EOR 1994 Delayed ("secondary") cerebral energy failure after acute hypoxia-ischemia in the newborn piglet: continuous 48-hour studies by phosphorus magnetic resonance spectroscopy. Pediatr Res 36:699-706

5. Blumberg RM, Cady EB, Wigglesworth JS, McKenzie JE, Edwards AD 1997 Relation between delayed impairment of cerebral energy metabolism and infarction following transient focal hypoxia-ischaemia in the developing brain. Exp Brain Res 113:130-137

6. Blumberg RM, Taylor DL, Yue X, Aguan K, Mckenzie J, Cady EB, Weiner CP, Mehmet H, Edwards AD 1999 Increased nitric oxide synthesis is not involved in delayed cerebral energy failure following focal hypoxic-ischemic injury to the developing brain. Pediatr Res 46:224-231

7. Yager JY, Brucklacher RM, Vannucci RC 1992 Cerebral energy metabolism during hypoxia-ischaemia and early recovery in immature rats. Am J Physiol 262:H672H677

8. Buchan A, Pulsinelli WA 1990 Hypothermia but not the N-methyl-D-aspartate antagonist, MK-801, attenuates neuronal damage in gerbils subjected to transient global ischemia. J Neurosci 10:311-316
9. Dietrich WD, Busto R, Alonso O, Globus MY, Ginsberg MD 1993 Intraischemic but not postischemic brain hypothermia protects chronically following global forebrain ischemia in rats. J Cereb Blood Flow Metab 13:541-549

10. Boris-Moller F, Smith ML, Siesjö BK 1989 Effects of hypothermia on ischemic brain damage: a comparison between preischemic and postischemic cooling. Neurosci Res Commun 5:87-94

11. Busto R, Dietrich WD, Globus MY-T, Ginsberg MD 1989 The importance of brain temperature in cerebral ischemic injury. Stroke 20:1113-1114

12. Busto R, Dietrich WD, Globus MY-T, Ginsberg MD 1989 Post-ischemic moderate hypothermia inhibits CA1 hippocampal ischemic neuronal injury. Neurosci Lett 101:299-304

13. Busto R, Dietrich WD, Globus MY-T, Vakdes I, Schenberg P, Ginsberg MD 1987 Small difference in intrischemic brain temperature critically determine the extent of ischemic neuronal injury. J Cereb Blood Flow Metab 7:729-738

14. Dietrich WD, Busto R, Valdes I, Loor Y 1990 Effects of normothermic versus mild hyperthermic forebrain ischemia in rats. Stroke 21:1318-1325

15. Green EJ, Dietrich WD, van Dijk F, Busto R, Markgraf CG, McCabe PM, Ginsberg MD, Schneiderman N 1992 Protective effects of brain hypothermia on behavior and histopathology following global cerebral ischemia in rats. Brain Res 580:197-204

16. Laptook AR, Corbett RJ, Sterett R, Burns DK, Tollefsbol G, Garcia D 1994 Modest hypothermia provides partial neuroprotection for ischemic neonatal brain. Pediatr Res 35(4 Pt 1):436-442

17. Williams GD, Dardzinski BJ, Buckalew AR, Smith MB 1997 Modest hypothermia preserves cerebral energy metabolism during hypoxia-ischemia and correlates with brain damage: a $31 \mathrm{P}$ nuclear magnetic resonance study in unanesthetized neonatal rats. Pediatr Res 42:700-708

18. Yager JY, Towfighi J, Vannucci RC 1993 Influence of mild hypothermia on hypoxicischemic brain damage in the immature rat. Pediatr Res 34:525-529

19. Sirimanne ES, Blumberg RM, Bossano D, Gunning M, Edwards AD, Gluckman PD, Williams CE 1996 The effect of prolonged modification of cerebral temperature on outcome after hypoxic-ischemic brain injury in the infant rat. Pediatr Res 39:591-597

20. Thoresen M, Bågenholm R, Løberg EM, Apricena F, Kjellmer I 1996 Posthypoxic cooling of neonatal rats provides protection against brain injury. Arch Dis Child 74:F3-F9

21. Sherwood NM, Timiras PS 1970 A stereotaxic atlas for the developing rat brain. University of California Press, Berkley and Los Angeles

22. Romijn HJ, Hofman MA, Gramsbergen A 1991 At what age is the developing cerebral cortex of the rat comparable to that of the full-term newborn human baby? Early Hum Dev 26:61-67

23. Alfaro V, Peinado VI, Palacios L 1994 Changes in plasma glucose, lactate, triglycerides and some non-protein nitrogen components induced by short-term hypothermia in the conscious rat. Comp Biochem Physiol 107:149-155

24. Minamisawa H, Mellergard P, Smith ML, Bengtsson F, Theander S, Boris-Moller F, Siesjo BK 1990 Preservation of brain temperature during ischemia in rats. Stroke 21:758-764

25. Carroll M, Beek O 1992 Protection against hippocampal CA1 cell loss by postischemic hypothermia is dependent on delay of initiation and duration. Metab Brain Dis 7:45-50

26. Coimbra C, Wieloch T 1994 Moderate hypothermia mitigates neuronal damage in the rat brain when initiated several hours following transient cerebral ischemia. Acta Neuropathol Berl 87:325-331

27. Colbourne F, Corbett D 1995 Delayed postischemic hypothermia: a six month survival study using behavioral and histological assessments of neuroprotection. J Neurosci 15:7250-7260

28. Thoresen M, Bagenholm R, Loberg EM, Apriccna F 1996 The stress of being restrained reduces brain damage after a hypoxic-ischaemic insult in the 7-day-old rat. Neuroreport 7:481-484

29. Colbourne F, Li H, Buchan AM 1999 Indefatigable CA1 sector neuroprotection with mild hypothermia induced 6 hours after severe forebrain ischemia in rats. J Cereb Blood Flow Metab 19:742-749

30. Huang FP, Zhou LF, Yang GY 1998 Effects of mild hypothermia on the release of regional glutamate and glycine during extended transient focal cerebral ischemia in rats. Neurochem Res 23:991-996

31. Taylor DL, Edwards AD, Mehmet H 1999 Oxidative metabolism, apoptosis and perinatal brain injury. Brain Pathol 9:93-117

32. Palmer C, Roberts RL, Towfighi J 1993 Allopurinol administered after inducing hypoxia-ischemia reduces brain injury in 7-day old rats. Pediatr Res 33:405-411

33. Karibe H, Chen SF, Zarow GJ, Gafni J, Graham SH, Chan PH, Weinstein PR 1994 Mild intraischemic hypothermia suppresses consumption of endogenous antioxidants after temporary focal ischemia in rats. Brain Res 649(1-2):12-18

34. Lei B, Tan X, Cai H, Xu Q, Guo Q 1994 Effect of moderate hypothermia on lipid peroxidation in canine brain tissue after cardiac arrest and resuscitation. Stroke 25:147-152

35. Lei B, Adachi N, Arai $\mathrm{T} 1997$ The effect of hypothermia on $\mathrm{H}_{2} \mathrm{O}_{2}$ production during ischemia and reperfusion: a microdialysis study in the gerbil hippocampus. Neurosci Lett 222:91-94

36. Beilharz EJ, Williams CE, Dragunow M, Sirimanne ES, Gluckman PD 1995 Mechanisms of delayed cell death following hypoxic-ischemic injury in the immature rat: evidence for apoptosis during selective neuronal loss. Mol Brain Res 29:1-14

37. Edwards AD, Yue X, Squier MV, Thoresen M, Cady EB, Penrice J, Cooper C, Wyatt JS, Reynolds EOR, Mehmet H 1995 Specific inhibition of apoptosis after cerebral hypoxia-ischaemia by moderate post-insult hypothermia. Biochem Biophys Res Commun 217:1193-1199

38. Colbourne F, Sutherland GR, Auer RN 1999 Electron microscopic evidence against apoptosis as the mechanism of neuronal death in global ischemia. $\mathrm{J}$ Neurosci 19:4200-4210 